\title{
REVISTA
}

\section{ANÁLISE DE MODELOS DIDÁTICOS DE ALUNOS EM UM CURSO ESPECIALIZAÇÃO LATO SENSU EM ENSINO DE CIÊNCIAS}

\section{ANALYSIS OF STUDENT TEACHING MODELS IN A GRADUATE SCIENCE TEACHING COURSE}

\author{
Edmundo Rodrigues Junior ${ }^{1}$ \\ Fabielle Castelan Marques ${ }^{2}$ \\ Flávio $\mathrm{Izo}^{3}$ \\ Paulo José Pereira de Oliveira ${ }^{4}$ \\ Tércio da Silva de Souza ${ }^{5}$
}

\begin{abstract}
${ }^{1}$ Instituto Federal do Espírito Santo - Campus Cachoeiro de Itapemirim; E-mail: edmundor@ifes.edu.br* ${ }^{2}$ Instituto Federal do Espírito Santo - Campus Cachoeiro de Itapemirim; E-mail: fabiellec@ifes.edu.br ${ }^{2}$ ${ }^{3}$ Instituto Federal do Espírito Santo - Campus Cachoeiro de Itapemirim; E-mail: fizo@ifes.edu.br ${ }^{3}$ ${ }^{4}$ Instituto Federal do Espírito Santo - Campus Cachoeiro de Itapemirim; E-mail: paulojoseo@ifes.edu.br ${ }^{4}$ ${ }^{5}$ Instituto Federal do Espírito Santo - Campus de Alegre; E-mail: tssouza@ifes.edu.br ${ }^{5}$
\end{abstract}

Artigo submetido em 05/03/2019, aceito em 15/06/2019 e publicado em 23/09/2019.

Resumo: Este trabalho tem como objetivo identificar os modelos didáticos pessoais de um grupo de alunos regularmente matriculados em um curso de Pós-graduação lato sensu em Ensino de Ciências. Aplicamos um questionário a 28 alunos, sendo 14 estudantes de ensino de química e 14 estudantes de ensino de física. A partir das respostas obtidas com este instrumento calculamos o grau de hibridismo dos modelos didáticos bem como o grau de coerência em relação ao paradigma construtivista. Constatamos que os modelos didáticos dos alunos de ensino de física são mais híbridos que os modelos didáticos apresentados pelos alunos de ensino química. Estes últimos apresentam um grau de coerência mais alinhados aos modelos espontaneísta e alternativo. Somente dois alunos apresentaram um grau de coerência negativo, o que pode indicar uma desconstrução em potencial do modelo didático tradicional.

Palavras-chave: Modelos Didáticos; hibridismo; construtivismo.

Abstract: This work aims to identify the personal didactic models of a group of students regularly enrolled on in-service science teaching. We applied a questionnaire to 28 students, with 14 students of chemistry and 14 students of physics. We obtained the degree of hybridism of didactic models and the degree of coherence in relation to constructivist paradigm. We found that the didactic models of physics students are more hybrids than didactic models presented by students of chemical. The latter have a degree of coherence that is more in line with the spontaneous and alternative models. Only two students presented a degree of negative coherence which may indicate a potential deconstruction of the traditional didactic model.

Keywords: Didactic Model; hybridism; construtivism. 


\section{INTRODUÇÃO}

Durante muito tempo os cursos de formação continuada privilegiaram atividades que negligenciavam a realidade da escola e dos professores. A visão essencialmente técnica e mecanicista do trabalho resultou em práticas formativas individualizadas com seus objetivos centrados nas atividades realizadas por trabalhador, desconsiderando os problemas das instituições e seus contextos de trabalho (GAMA; TERRAZZAN, 2011, p.2).

Estudos da Organização das Nações Unidas para a Educação, a Ciência e a Cultura (UNESCO) reconhecem que a educação continuada na América Latina tem pouca relevância e articulação, não leva em conta a heterogeneidade de situações de professores, nem considera a realidade das escolas e os desafios práticos de ensino (PREAL, 2013, p.115).

No Brasil, as orientações para a formação continuada de professores aparecem na Lei de Diretrizes e Bases da Educação Nacional (LDB, lei n.9394/96) e nas diretrizes curriculares nacionais (BRASIL, 2001) e no Plano Nacional de Educação (PNE).A LDB legitima a formação continuada para promover a valorização dos educadores através do aperfeiçoamento profissional continuado.

As diretrizes curriculares nacionais orientam sobre a importância da formação em serviço porque o conhecimento passou a ser um dos recursos fundamentais que "tende a criar dinâmicas sociais e econômicas, e também novas políticas, o que pressupõe que a formação deva ser complementada ao longo da vida, o que exige formação continuada" (BRASIL, 2001, p.9).

De acordo com Porlán e Rivero (1998) e García e Porlán (2000), a formação de professores deve se basear em quatro aspectos fundamentais: os problemas práticos dos professores, suas concepções e experiências, as influências de outras fontes de conhecimentos e as inter-relações que se estabelecem entre elas. Assim, espera-se que os professores possam:
[...] conhecer seu próprio modelo didático pessoal; observar criticamente sua prática e identificar os problemas inerentes a ela; contrastar através de experiências próprias, e com as de outros profissionais, hipóteses de soluções para os problemas identificados; colocar em prática as hipóteses e saber avaliar as mudanças bem como contrastar os resultados obtidos com base na avaliação das hipóteses de partida, e estabelecer conclusões sobre seu modelo didático pessoal (HYGINO; MOURA; LINHARES, 2014, p.44).

No presente trabalho, apresentamos os resultados de uma pesquisa na qual utilizamos o questionário proposto por Santos Jr. (2009) e os parâmetros construídos por Ayres-Pereira e Marcondes (2013). Nossa pesquisa tem como objetivo identificar os modelos didáticos de estudantes de ensino de química e ensino de física de um curso de pós-graduação lato sensu em ensino de ciências de uma instituição federal de ensino.

A pesquisa identificou e analisou o grau de heterogeneidade dos modelos didáticos pessoais dos alunos bem como grau de coerência em relação ao paradigma construtivista. Além disso, comparamos os resultados dessas medidas entre os alunos de ensino de física e ensino de química, propondo intervenções para alcançar o modelo de ensino alternativo, considerado desejável por Porlán e Rivero (1998).

\section{REFERENCIAL TEÓRICO}

Segundo Porlán e Rivero (1998) o conhecimento profissional dos professores é constituído de quatro componentes de saberes:

(1) Os saberes acadêmicos, que são aqueles alcançados pelo professor durante seu processo de formação inicial. São formados pelos tópicos curriculares das disciplinas, pelos saberes relacionados aos conteúdos a serem ensinados e pelos saberes psicológicos, didáticos e epistemológicos. 
(2) desenvolvidas pelos professores durante o exercício da sua profissão. São saberes que se referem aos métodos de ensino, a aprendizagem dos alunos, a natureza dos conteúdos, o papel da programação e da avaliação, os fins e objetivos desejáveis, e os que são compartilhados no ambiente escolar.

(3) As rotinas e guias de ação, que são situações incorporadas pelos professores de forma inconsciente e que ajudam a solucionar problemas do dia- a- dia do docente e são mais resistentes à mudanças. Esses saberes se referem ao conjunto de esquemas implícitos que predizem o curso imediato dos acontecimentos na aula e a maneira de como abordá-lo. As ações dos professores para manter o silêncio dos alunos na sala de aula, mesclando transmissão de conteúdos com explicação e sugerindo que os alunos resolvam listas de exercícios, são exemplos de rotinas e guias de ação.

(4) As teorias implícitas, que podem explicar as ações dos docentes, entretanto eles geralmente não são conscientes delas. Por exemplo, o professor pode não ter consciência da teoria que embasa uma estratégia de ensino tradicional (quase que exclusivamente na transmissão verbal do conteúdo disciplinar). Esta forma de pensar e de agir pressupõe uma teoria de apropriação da aprendizagem formal de significados onde se ensina para a memorização de conteúdos e sem considerar os conhecimentos prévios dos alunos (PORLÁN; RIVERO, 1998, p.62).

Para Porlán e Rivero (1998, p.63) “o conhecimento profissional dominante costuma ser o resultado de uma justaposição destes quatro tipos de saberes, que são de naturezas diferentes, e gerados em momentos e contextos distintos".

De acordo com Harres et al. (2005), o planejamento e a execução de uma aula do professor se relacionam com seu saber ou conhecimento profissional. Assim, este fazer pedagógico reflete o modelo de apoio do professor (HYGINO, 2015).
Para Porlán e Rivero (1998), as atuações e concepções dos professores frente ao processo de ensino-aprendizagem, podem ser representadas por meio de quatro modelos didáticos: 1) o tradicional, 2) o tecnológico, 3) o espontaneísta, caracterizados como modelos de transição, e 4) o modelo investigativo.

O modelo didático tradicional se caracteriza pela transmissão de conhecimentos, na qual os conteúdos são pensados em sequências lineares e rígidas. A metodologia é a transmissão verbal do professor e uso quase exclusivo do livrotexto. Avalia-se a memorização mecânica dos conteúdos e não considera o conhecimento prévio do aluno. O professor tem papel ativo, enquanto o aluno, passivo.

$\mathrm{O}$ modelo tecnológico tem o objetivo de ensinar adequadamente as ciências, utilizando-se de materiais didáticos atualizados e um planejamento metodológico rigoroso. A avaliação tem como objetivo quantificar a aprendizagem e verificar a eficiência dessa sistemática de ensino. $\mathrm{O}$ aluno tem, ainda, papel passivo.

No modelo espontaneísta, as ideias dos alunos têm ênfase, os conteúdos atendem aos seus interesses, as atividades não são previamente planejadas, valoriza-se apenas a experiência dos professores, e a avaliação se dá através da participação dos alunos.

O modelo investigativo, por sua vez, propõe um ensino no qual tanto alunos quanto professores exercem um papel ativo. Enfatizam-se as situações-problema que exigem dos alunos posturas investigativas, nas quais devem elaborar hipóteses e propor soluções. As atividades são contextualizadas, com temas socialmente relevantes e com incentivo à atuação dos alunos. A avaliação tem como objetivo identificar as dificuldades dos alunos e promover reflexões sobre a construção dos conhecimentos dos estudantes.

Ainda segundo Porlán e Rivero (1998), esse conhecimento é constituído pelo conjunto de crenças, conhecimentos específicos, rotinas e técnicas que, na sua 
forma desejável, envolveria a integração dessas dimensões de forma complexa, crítica, evolutiva e investigativa em sala de aula.

Além disso, deve-se considerar as ideias sobre ensino e aprendizagem apresentadas pelos professores antes de iniciar seu processo de formação, sendo essas, possivelmente, o ponto de partida dos processos formativos. Portanto, a formação dos professores seria um processo de (re) construção gradual e contínua de seu conhecimento profissional, cuja intencionalidade destina-se à construção de estratégias para a superação dos problemas da prática docente. Esta construção, concebida evolutivamente, deve desenrolarse em um contexto de explicitação, reflexão e discussão sobre seu conhecimento profissional prévio e seu confronto com novas concepções, para possibilitar mudanças ao mesmo tempo conceituais, metodológicas e atitudinais dos professores (HARRES et al, 2008).

Nesse caso, a evolução é entendida como a passagem de concepções e ações docentes, inicialmente simples e, na maioria das vezes, implícitas, relacionadas com o modelo didático tradicional, para outras progressivamente mais complexas e conscientes, "embasadas em uma visão integradora das relações entre ciência, ideologia e cotidianidade e no desenvolvimento dos princípios de autonomia, diversidade e negociação rigorosa e democrática de significados" (PORLÁN; RIVERO, 1998, p. 56).

\section{CONTEXTO DA PESQUISA E PROCESSOS METODOLÓGICOS}

A pesquisa foi desenvolvida no primeiro semestre de 2019, dentro da disciplina Tópicos Especiais de Ensino de Ciências, que pertence a um curso de pósgraduação lato sensu em Ensino de Ciências Naturais.

O curso pós-graduação supracitado possui carga horária de 360 horas e tem como objetivo: possibilitar aos profissionais da docência um aperfeiçoamento voltado ao Ensino de Ciências Naturais; com ênfase em Física e em Química; aprofundar conhecimentos específicos em Física e Química; desenvolver as habilidades comunicativas e da capacidade de expressão, oral e escrita, nos diferentes, sistemas simbólicos de representação científica; promover a valorização, na dimensão da formação continuada de professores da área de Ciências Naturais, a partir de conhecimentos acerca da profissionalização docente; ampliar conhecimentos teórico e metodológico a partir de referenciais para análise e avaliação de materiais alternativos e programas educativos nas ciências da natureza; contribuir para com a produção de conhecimento na área de Ensino de Ciências Naturais com ênfase em física e química; discutir as contribuições de resultados de pesquisas que estabelecem o papel das concepções alternativas na aprendizagem, que problematizam as relações entre ciência, tecnologia e sociedade; articular os benefícios e as especificidades das experiências de ensino e aprendizagem em espaços formais e não formais; adotar e desenvolver ações afirmativas para o acesso e permanência de discentes negros, indígenas e/ou com deficiência ou necessidades específicas.

A disciplina em que foi realizada a pesquisa possui carga horária de 15 horas distribuídas em quatro encontros e tem como um dos objetivos discutir os saberes dos professores e compreender os seus respectivos modelos didáticos pessoais.

No primeiro encontro (aula inaugural) foi feito uma discussão sobre as relações entre teoria e prática na formação de professores. No segundo encontro trabalhamos aspectos da legislação educacional (Lei de Diretrizes e Bases, Parâmetros Curriculares Nacionais, Base Nacional Curricular Comum) no contexto do ensino de ciências

No terceiro encontro foi aplicado o questionário elaborado por Santos Jr. 
(2009) ${ }^{1}$. O instrumento é constituído de 20 proposições distribuídas nas dimensões de ensino: objetivo; conteúdo; contribuição do aluno; metodologia e avaliação e teve como objetivo identificar as concepções dos modelos didáticos dos alunos de ensino de química e ensino de física. $\mathrm{O}$ aluno teria que assinalar a concordância ou discordância com as afirmações apresentadas, expressando: 3 (concordância total); 2 (concordância parcial); 1 (discordância parcial); ou 0 (discordância total) para cada proposição: $\mathrm{O}$ questionário foi aplicado para 28 alunos sendo 14 alunos de ensino de química e 14 alunos de ensino de física.

No quarto encontro mostramos características e exemplos de duas metodologias ativas (estratégia de ensino estudo de caso e sequência de ensino investigativo). Nesta pesquisa mostramos os resultados e discussões dos dados coletados no terceiro encontro.

\section{RESULTADOS E DISCUSSÃO}

A maioria dos nossos alunos concordou com as proposições de todos os modelos didáticos, nas diferentes dimensões do ensino. Esse resultado converge com os resultadosobtidos porGuimarães, Echeverria e Moraes (2006), Cavalcante e Silva (2008); Santos Jr. e Marcondes (2010) e AyresPereira e Marcondes (2016). Os autores supracitados relatam em suas pesquisas a existência de modelos ecléticos nas crenças pedagógicas dos professores.

A pesquisa de Hygino, Moura e Linhares (2014) encontrou, nas falas de um aluno licenciando, mesclas de concepções que apontam características dos modelos tradicional, espontaneísta e alternativo de ensino.

Para compreender melhor a diversidade das respostas dos nossos alunos em relações às dimensões do ensino, calculamos o grau de hibridismo $(\mathrm{GH})$ do modelo didático, definido, segundo Ayres-

1 Vide anexo.
Pereira e Marcondes (2016) como a medida da heterogeneidade dos modelos didáticos que constituem o modelo didático pessoa, ou seja, o GH permite identificar se os professores possuem ou não modelos didáticos diversificados. Matematicamente, o GH é calculado pela equação: $\mathrm{GH}=$ $(\mathrm{T}+\mathrm{C}+\mathrm{E}+\mathrm{A})$ / 5, onde $\mathrm{T}, \mathrm{C}, \mathrm{E}, \mathrm{A}$, representando, respectivamente, o número de concordâncias (2 ou 3) dos modelos didáticos Tradicional, Tecnológico, Espontaneísta e Alternativo. Esse valor varia de 1 a 4 , sendo que o valor 4 representa o grau máximo de hibridismo e 1 representa o grau mínimo de hibridismo.

Para entender um pouco mais o significado da equação $\mathrm{GH}=(\mathrm{T}+\mathrm{C}+\mathrm{E}+\mathrm{A}) /$ 5 , vamos explicar um caso de um estudante que obteve um $\mathrm{GH}=4$ : Verificamos no questionário do anexo 1 a presença de 20 itens divididas em cinco dimensões (Objetivo, Conteúdo, Contribuição, Metodologia e Avaliação). Se o estudante obteve $\mathrm{GH}=4$ foi porque concordou com todos itens das cinco dimensões supracitadas, isto é, assinalou 2 ou 3 (entre as opções $0,1,2$ e 3 ). Dessa forma temos um total de 20 respostas com 2 ou 3. Assim $(\mathrm{T}+\mathrm{C}+\mathrm{E}+\mathrm{A})=20$, resultando em 20/5 $=4$. O mesmo raciocínio é aplicado para os demais resultados. Os resultados do GH obtidos com alunos de ensino de química e ensino de física são apresentados no Gráfico 1 :

Gráfico 1: Grau de hibridismo dos alunos de ensino de química e ensino de física

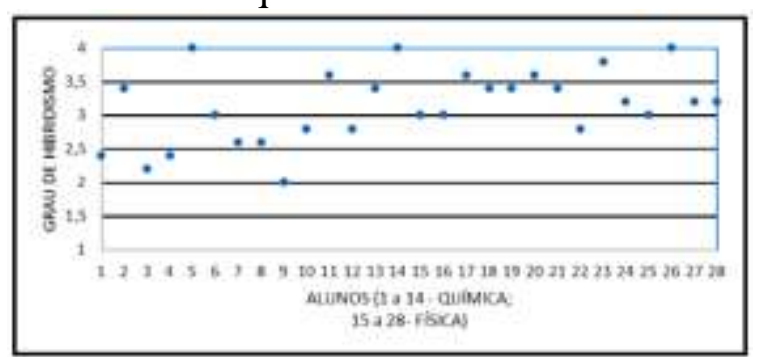

Fonte: Elaborado pelo autor.

Dezenove (68\%) dos alunos apresentaram $\mathrm{GH} \geq 3,0$, o que significa que concordaram com a maioria das proposições de ao menos três modelos didáticos, isto é, 
concordaram com proposições antagônicas em relação ao ensino. Comparando o $\mathrm{GH}$ dos professores de física e química, verificamos que seis $(43 \%)$ dos professores de química apresentaram $\mathrm{GH} \geq 3,0$, enquanto que treze $(93 \%)$ dos professores de física apresentaram $\mathrm{GH} \geq 3,0$.

Constatamos, portanto, que os modelos didáticos dos alunos de ensino de física são mais híbridos que os modelos didáticos apresentados pelos alunos de ensino química. Nove (64\%) dos alunos de ensino de física não possuem formação em licenciatura em física. Desses nove, seis são formados em cursos de engenharias e nunca lecionaram, enquanto que outros três alunos são formados em licenciatura em matemática, tendo quatro anos ou menos de experiência como docente.

Tais dados sinalizam um provável desconhecimento das dimensões essenciais de um plano de aula de física como objetivos da disciplina, conteúdos para ensinar, contribuição das concepções e interesses do aluno em relação à escolha de conteúdo, metodologia e avaliação. Talvez a falta de conhecimento sobre tais dimensões, foi a responsável pela dificuldade apresentada pelos professores para escolher características das dimensões coerentes com apenas um modelo didático.

Segundo Porlán e Rivero (1998), o modelo didático pessoal do professor evolui do tradicional ao alternativo ou investigativo. Os modelos Tecnológico e o Espontaneísta são modelos de transição e estão alinhavados com as dimensões de ensino associadas ao paradigma construtivista.

Para o Modelo Espontaneísta, tais dimensões orientam: desenvolver um cidadão crítico, ético e atuante no mundo em que vive (objetivo em ensinar); ensinar conceitos presentes nos fenômenos que se apresentam no cotidiano do aluno (conteúdos a ensinar); reconhecer apenas os interesses do aluno, pois dessa forma $o$ estudo das disciplinas pode ser mais atraente e significativo para o aluno (contribuição das concepções e interesses do aluno em relação à escolha dos conteúdos); na proposta de atividades que estimulem a capacidade do aluno de analisar, julgar, criticar e exercer sua cidadania (metodologia); privilegiar a mudança atitudinal do aluno, as habilidades e competências construídas no processo de ensino- aprendizagem (avaliação). ${ }^{2}$

Para o modelo Alternativo, tais dimensões orientam: enriquecer progressivamente os conhecimentos dos alunos conseguindo fazer leituras cada vez mais complexas do mundo em que vive ( objetivo em ensinar); selecionar conhecimentos que permitam a integração nos níveis científico, social, histórico e ambiental (conteúdos a ensinar); reconhecer as concepções e os interesses que devem nortear a escolha dos conteúdos que irão ser trabalhados (contribuição das concepções e interesses do aluno em relação à escolha dos conteúdos); propor situações problemas e oferecer condições para o aluno encontrar soluções para o problema através de metodologias ativas (metodologia); avaliar a evolução dos conhecimentos dos alunos em relação ao processo de ensino-aprendizagem (avaliação). ${ }^{3}$

O Currículo de Ciência Natureza do Estado do Espírito Santo está alinhado com paradigmas construtivistas (modelos de ensino espontaneísta e alternativo), conforme a citação abaixo em relação à dimensão de ensino avaliação:

Mediante seus resultados, os
estudantes tomam consciência de sua
progressão na aprendizagem e
necessidades, e, ao mesmo tempo, os
professores os utilizam como subsídio
para a tomada de decisões, a avaliação
da sua própria prática e a busca de
outras formas de planejamento,
conteúdos, estratégias e formas de
abordar os contextos, visando oferecer
novas possibilidades de aprendizagem.
(SEDU, 2018, p.38).

2. Dimensões de ensino do modelo didático espontaneísta retirada de Santos Jr. (2009).

3. Dimensões de ensino do modelo didático alternativo retirada de Santos Jr.(2009) 
Nesse sentido, compreender a convergência das respostas dos alunos de ensino de física e ensino de química em relação ao paradigma construtivista pode auxiliar o professor formador a elaborar estratégias didáticas que promova nos estudantes da pós-graduação atitudes coerentes com os modelos espontaneísta e alternativo. Com esse objetivo, calculamos o grau de coerência (GC) em relação ao paradigma construtivista dos alunos de física e química. Segundo Ayres- Pereira e Marcondes (2016) o GC é dado pela expressão: $(\mathrm{GC}) \mathrm{E} / \mathrm{A}=[\mathrm{n}(\mathrm{E}+\mathrm{A})+\mathrm{m}(\mathrm{T}+$ $\mathrm{C})]-[\mathrm{x}(\mathrm{E}+\mathrm{A})+\mathrm{z}(\mathrm{T}+\mathrm{C})]$

Onde:

$\mathrm{n}$ : número de afirmativas com atribuição 2 ou 3 (concordância), para uma dada dimensão dos modelos E e A;

$\mathrm{m}$ : número de afirmativas com atribuição 0 ou 1 (discordância), para uma dada dimensão dos modelos $\mathrm{T}$ ou $\mathrm{C}$;

$\mathrm{x}$ : número de afirmativas com atribuição 0 ou 1(discordância), para uma dada dimensão dos modelos $\mathrm{E}$ ou $\mathrm{A}$;

$\mathrm{z}$ : número de afirmativas com atribuição 2 ou 3 (concordância), para uma dada dimensão dos modelos $\mathrm{T}$ ou $\mathrm{C}$

Calculado dessa maneira, o grau de coerência com os modelos E e A, em cada dimensão do ensino, possui o valor máximo igual a 4 , sendo atingido quando $n=2, m=2$, $\mathrm{x}=0$ e $\mathrm{z}=0$. $\mathrm{O}$ valor mínimo é -4 , sendo atingido quando $\mathrm{n}=0, \mathrm{~m}=0, \mathrm{x}=2$ e $\mathrm{z}=2$. Para entender melhor o cálculo do grau de coerência vamos detalhar o caso em que $n=$ $2, \mathrm{~m}=2, \mathrm{x}=0$ e $\mathrm{z}=0$.

Verificando o questionário do anexo 1, observamos que em cada dimensão (Objetivo, Conteúdo, Contribuição, Metodologia e Avaliação), há quatro itens. Os dois primeiros itens de cada dimensão referem-se aos modelos tradicional (T) e tecnológico (C), enquanto que os dois últimos correspondem aos modelos espontaneísta (E) e alternativo (A). Então n $=2$ indica que o estudante marcou 2 ou 3 nas duas últimas questões; $m=2$ indica que marcou 0 ou 1, nas duas primeiras questões. Enquanto que $\mathrm{x}=0$, indica que o estudante não marcou 0 ou 1 nas duas últimas questões e finalmente, $\mathrm{z}=0$ indica que o estudante não marcou 2 ou 3 nas duas primeiras questões. Logo: $\mathrm{n}(\mathrm{E}+\mathrm{A})=2 ; \mathrm{m}$ $(\mathrm{T}+\mathrm{C})=2 ; \mathrm{x}(\mathrm{E}+\mathrm{A})=0$ e $\mathrm{z}(\mathrm{T}+\mathrm{C})=0$. Substituindo na fórmula, temos: $(\mathrm{GC}) \mathrm{E} / \mathrm{A}=$ 4.

Os resultados do grau de coerência dos alunos de ensino de física e de química são apresentados na tabela 1:

Tabela 1: Resultado do GC dos alunos

\begin{tabular}{|c|c|c|c|c|c|c|c|c|}
\hline \multirow{3}{*}{ DEMENSAO } & \multicolumn{8}{|c|}{ NUMERO DE ALCNOS (N-28) } \\
\hline & \multicolumn{2}{|c|}{000} & \multicolumn{2}{|c|}{$\omega 00$} & \multicolumn{2}{|c|}{$G C=2$} & \multicolumn{2}{|c|}{$\mathrm{GC}=4$} \\
\hline & QUM & Fis & QUEM & Fis & Qum & F1S & QUEM & FIS \\
\hline Objetwo & e & Q & 11 & 13 & 3 & 1 & Q & Q \\
\hline Coutriabs & Q & Q & a & 12 & 1 & 2 & 1 & Q \\
\hline $\begin{array}{l}\text { Contribueģa do } \\
\text { shung }\end{array}$ & $\hat{e}$ & $\hat{i}$ & 4 & 6 & 2 & i & 1 & $\hat{i}$ \\
\hline $\begin{array}{l}\text { Metodologia } \\
\text { Avalasio }\end{array}$ & l & $\hat{e}$ & $\frac{6}{7}$ & ${ }_{10}^{8}$ & $\frac{4}{2}$ & $\frac{3}{4}$ & $\frac{4}{4}$ & 1 \\
\hline
\end{tabular}

Fonte: Elaborada pelo autor.

Percebemos que o número alunos de ensino química que apresentaram $\mathrm{GC}=4$ é maior que o número de alunos de ensino de física que apresentaram $\mathrm{GC}=4$. Acreditamos que esta diferença aconteceu devido à formação profissional dos estudantes porque dos quatorze alunos de ensino química, dez são licenciados em química e/ou biologia e possuem experiências em sala de aula. No site de uma instituição de ensino, onde alguns alunos da pós-graduação se graduaram em Licenciatura em Ciências Biológicas, existe uma orientação para que "as atividades acadêmicas capacitam a intervir na realidade brasileira e educam cidadãos comprometidos com a ética, a qualidade da aprendizagem e a cidadania"4. Percebemos que o objetivo das atividades acadêmicas está associado aos modelos de ensino espontaneísta e alternativo.

Um exemplo que será aplicado na pós-graduação em ensino de ciências e que pode facilitar a transição dos professores de física para o modelo alternativo, consiste na utilização de metodologias ativas.

4 Vide: http://www.saocamiloes.br/centrouniversitario/cursos/licenciatura/cienciasbiologicas.html 
As metodologias ativas representam o ponto de partida para progressão de processos mais desenvolvidos de reflexão e reestruturação da prática docente (MORAN, 2015). Freire (2009) salienta, em seus escritos, a importância de superar a "educação bancária" e dar lugar a uma educação cuja aprendizagem seja centrada no aluno. As metodologias ativas são processos pedagógicos que enfatizam o aluno, diferente do modelo didático tradicional. Essa metodologia possibilita uma maior integração entre alunos e professores (BERBEL, 2011). A metodologia ativa é a "[...] inter-relação entre educação, cultura, sociedade, política e escola, sendo desenvolvidas por meio de métodos ativos e criativos, centrados na atividade do estudante com a intenção de propiciar a aprendizagem" (BACICH; (MORAN, 2018, p. 6). Neste caso, o professor tem o papel de facilitar o processo de construção do conhecimento a fim de que os discentes consigam alcançar os objetivos esperados.

Um tipo de metodologia ativa, a "Sequência de Ensino Investigativa" (SEI) ${ }^{5}$ será aplicada na disciplina Experimentos e Recursos Didáticos em Física I, cuja ementa envolve conteúdos de física moderna como fótons e ondas de matéria. Espera-se que com o envolvimento nas aulas e o auxílio do professor mediador, o aluno de física possa entender e aplicar propostas de ensino alinhadas com o paradigma construtivista aumentando assim o número de alunos com $\mathrm{GC}=4$.

Somente dois alunos (um de ensino de física e outro de ensino de química) apresentaram um $\mathrm{GC}<0$ o que pode indicar uma desconstrução em potencial do modelo didático tradicional ou talvez, conforme Santos Jr; Marcondes (2010) "a superação

5 A Sequência de ensino investigativa (SEI) compreende uma sequência de atividades, dentre elas uma problematização inicial contextualizada, com intuito de fazer com que os alunos utilizem seus conhecimentos prévios para iniciar os novos, entendam os saberes científicos e alcancem gradativamente a alfabetização científica. Para uma compreensão melhor ver: Carvalho (2011). do modelo de ensino tradicional, centrado no professor". O resultado negativo do GC obtido em nossa pesquisa pode ser considerado um avanço da incorporação da metodologia vigente nas aulas da pósgraduação neste trimestre. Os professores que estão lecionando neste período têm sugerido atividades que priorizem a participação efetiva dos alunos

O professor de Tópicos Especiais em Ensino de Ciências orientou planos de aula que envolvessem estudos de casos científicos, sócio-científicos e históricos. Transmissão de ondas eletromagnéticas, rotações, interpretação de rótulos nutricionais e história das máquinas simples, foram tópicos presentes nos estudos de caso.

O professor de Tópicos Especiais de Física I tem trabalhado conteúdos de física quântica (fóton, radiação de corpo negro, efeito Compton) utilizando a pressupostos da metodologia Peer Instruction ${ }^{6}$ (aprendizagem por colegas). Inicialmente são apresentados um conjunto de questões sobre física quântica (ver anexo 2), para os estudantes devem tentarem responder individualmente utilizando as informações obtidas na internet ou outra fonte de pesquisa disponível. Em seguida, eles devem discutir em pares suas respostas e, se necessário, após a discussão, revisar suas repostas. Após este momento, o professor pergunta para os alunos suas repostas e vai anotando as respostas no quadro. Ao final, se necessário for, o professor formador complementa as informações e inclui uma explicação extra sobre o assunto.

Os docentes da disciplina Tópicos especiais de Química realizaram uma exposição da importância da História da Química nas aulas, argumentando do ponto de vista da epistemologia da ciência, natureza mutável das ideias científicas e da contextualização frente às legislações de

6 O Peer Instruction ou aprendizagem por colegas é uma metodologia ativa criada por Eric Mazur na década de 1990 que tem como objetivo "explorar a interação entre os estudantes durante as aulas expositivas" (MAZUR, 2015, P.10) 
educação no Brasil (LDB e BNCC). Esta aula foi avaliada por uma resenha de um artigo sobre como os livros didáticos abordam história da química. Em outro encontro, abordaram o valor da alquimia na evolução da química até a introdução da química moderna de Boyle e Lovoisier. Neste encontro, utilizaram ainda a experimentação e construção de um quiz usando a ferramenta Goconqr ${ }^{7}$.

No decorrer do curso iniciou-se um experimento para ser aplicado em sala de aula envolvendo agricultura e História da Química. Os alunos se dividiram em três grupos e irão construir artigos abordando: história da fotossíntese e respiração, história do ciclo do nitrogênio e influência do $\mathrm{pH}$ do solo. Todos estes temas serão associados aos resultados experimentais, sempre com foco na história da química. $\mathrm{O}$ artigo (avaliação final da disciplina) será item de avaliação de maior peso. $\mathrm{O}$ material produzido será submetido à revistas da área.

No último encontro, os alunos de ensino de química discutirão aspectos da história da Radioatividade, personagens históricos, interdisciplinaridade, aspectos éticos. Os pós-graduandos irão construir uma linha do tempo sobre o tema.

$\mathrm{O}$ professor de Informática no ensino de ciências solicitou aos alunos que elaborassem sequências didáticas que contemplasse as Novas Tecnologias (NTICs), aproveitando as tendências modernas que propiciam a motivação no uso de tecnologias por parte dos alunos. Podcast simuladores virtuais de experimentos, e ambiente virtuais de aprendizagem tais como o Google Classroom e Moodle são exemplos das NTICs utilizadas nas sequências didáticas dos estudantes. Os discentes puderam abordar estratégias específicas às suas áreas de atuação, considerando seus componentes curriculares e, concomitantemente,

\footnotetext{
7 GoConqr (pronunciado 'gou conquer') é uma plataforma virtual de ensino. $\mathrm{O}$ nome Goconqr originalmente vem das palavras inglesas 'Go' (Ir) e 'Conquer' (Conquistar).
}

potencializando o processo de produção de conhecimento.

No último encontro da disciplina tópicos especiais em Ensino de Ciências, os estudantes apresentaram seminários sobre o tema modelos didáticos. Cada grupo ficou responsável por apresentar um artigo sobre o tema:

Grupo 1- Modelos didáticos: um referencial para reflexão sobre as crenças didáticas de professores; escrito pelos autores: Novais; Siqueira; Marcondes (2011).

Grupo 2- Modelos didáticos na formação inicial de professores de física: uma apreciação na perspectiva da análise do discurso; de Hygino; Moura; Linhares (2014).

Grupo 3- Modelos didáticos predominantes na formação inicial de professores de química e física revelados pela análise de sequências didáticas; escrito pelos autores Hygino; Marcelino; Linhares (2014)

Grupo 4- Modelos didáticos presentes na formação de futuros professores de química e física da região norte do estado do Rio de Janeiro, Brasil: encontros e desencontros entre concepções e formação, escrito por Hygino; Marcelino; Linhares (2013)

Grupo 5- Análise do modelo didático de estudantes de Licenciatura em Química e Ciências Biológicas e propostas para $\mathrm{o}$ processo formativo; de Ayres-Pereira et. al. (2016)

Grupo 6- O modelo didático de professores de ciências e suas concepções de ensino e aprendizagem; escrito pelos autores Ayrespereira; Marcondes (2013).

Após a exposição do conteúdo, o professor formador responsável pela disciplina Tópicos Especiais em Ensino de Ciências mostrou a correspondência entre os modelos didáticos e os itens das dimensões de ensino presentes no questionário do anexo. Em seguida, apresentou-se o resultado do Grau de Hibridismo e Grau de Coerência dos estudantes de ensino de química e ensino de física (vide gráfico $1 \mathrm{e}$ tabela 1). A interação da turma foi considerada satisfatória, os estudantes queriam saber o valor do seu GH e GC. Foi 
posteriori das respostas dos alunos poderão ser utilizados com o objetivo de complementar essa pesquisa. Essas informações poderiam orientar outros formadores na melhorias e acertos nos cursos ofertados.

Durante os momentos de debates em torno dos artigos trabalhados, os alunos tiveram a oportunidade de refletir sobre seus próprios modelos didáticos. A atividade de apresentar o artigo para seus colegas contribuiu para que os alunos pudessem compreender sobre sua prática (futura ou atual) na sala de aula.

\section{REFERÊNCIAS}

AYRES-PEREIRA, T.I. MARCONDES, M.E. O modelo didático de professores de ciências e suas concepções de ensino e aprendizagem. Enseñanza de las Ciencias, v. Extra, p. 223-228, 2013.

AYRES-PEREIRA, T.I, MARCONDES, M. E., MONTANHA, M. A.; BEZERRA, R.G. Análise do modelo didático de estudantes de Licenciatura em Química e Ciências Biológicas e propostas para o processo formativo.2016. Disponível em: http://www.eneq2016.ufsc.br/anais/resumos /R1271-1.pdf. Acesso em 25/05/2019.

BACICH, L; MORAN, J. Metodologias Ativas para uma Educação Inovadora: Uma Abordagem Teórico-Prática. São Paulo: Penso Editora, 2018.

BRASIL. Ministério da Educação. Lei de Diretrizes e Bases da Educação Nacional. Brasília, 1996. Disponível em $<$ http://portal.mec.gov.br/arquivos/pdf/ldb.p df>, acesso em 28 ago. 2013.

BRASIL. Parecer CNE/CP 009/2001 Institui as Diretrizes Curriculares Nacionais para a Formação de Professores da Educação Básica, em nível superior, curso de licenciatura, de graduação plena. 2001. Disponível em: <http://portal.mec.gov.br/cne/arquivos/pdf/0 09.pdf> Acesso em: 02 set.2013.

BERBEL, N. A. N. As metodologias ativas e a promoção da autonomia de estudantes. Semina: Ciências Sociais e Humanas, v. 32, n. 1, p. 25-40, 2011.

\section{CARVALHO, A.M. Ensino e} aprendizagem de Ciências: referenciais teóricos e dados empíricos das sequências de ensino investigativas- SEI. In: Marcos Daniel Longhini. (Org.) O Uno e o Diverso na Educação. Uberlândia: EDUFU, 2011.

FREIRE, P. Pedagogia da Autonomia. 36. ed, São Paulo: Paz e Terra, 2009.

GAMA, M. E. TERRAZZAN, E.. A Formação continuada dos professores em escolas públicas: aspectos característicos de sua organização. EFDeportes.com, v. 16, n. 159, 2011.

GARCÍA, J. E.; PORLÁN, R. Ensino de ciências e prática docente: uma teoria do conhecimento profissional. Caderno Pedagógico, Lajeado, n. 3, 2000, p. 7-42.

GUIMARÃES, G. M. A. \& ECHEVERRÍA, A. R. Modelos didáticos no discurso de professores de Ciências. Investigações em Ensino de Ciências, 11(3), 303-322.

HARRES, J. B. S. et al, A evolução das concepções de futuros professores sobre a natureza e as formas de conhecer as ideias dos alunos. In: ENCONTRO NACIONAL DE PESQUISA EM EDUCAÇÃO EM CIÊNCIAS, 5, 2005, Bauru, Atas... Associação Brasileira de Pesquisa em Educação em Ciências 2005, p.1-12

HYGINO, C. B. Reflexões na formação inicial de professores de Física: avaliação da eficácia do método de Estudos de Caso para promover capacidades necessárias à prática docente. 2015. 256f. Tese (Doutorado em Ciências Naturais, Ensino de Ciências) - Programa de Pós Graduação 
em Ciências Naturais, UENF, Campos dos Goytacazes.

HYGINO,

C.B.; MOURA,

S.A.;

LINHARES, M.P. Modelos didáticos na formação inicial de professores de física: uma apreciação na perspectiva da análise do discurso. Ciênc. educ. (Bauru). 2014, vol.20, n.1, pp.43-59.

HYGINO, C.B; MOURA, S.A.; LINHARES; M.P. Modelos didáticos na formação inicial de professores de física: uma apreciação na perspectiva da análise do discurso. Ciência e Educação. Bauru, v. 20, n. 1, p. 43-59, 2014.

HYGINO; MARCELINO, V.S.; LINHARES, M. P. Modelos didáticos presentes na formação de futuros professores de química e física da região norte do estado do Rio de Janeiro, Brasil: encontros e desencontros entre concepções e formação. Revista Electrónica de Investigación en Educación en Ciencias. v. 8, n 2, p. 49-58, dez 2013.

MAZUR, E. Peer Instruction: A revolução da aprendizagem ativa. Tradução: Anatólio Laschuk- Porto Alegre: Penso, 2015.

MORÁN, J. Mudando a educação com metodologias ativas. Coleção Mídias Contemporâneas.

Convergências Midiáticas, Educação e Cidadania: aproximações jovens, v. 2, p. 1533, 2015.

NOVAIS, R.M; SIQUEIRA; C.T.; MARCONDES, M.E. Modelos Didáticos: um referencial para reflexão sobre as crenças didáticas de professores. 2011. Disponível em http://www.nutes.ufrj.br/abrapec/viiienpec/r esumos/R0517-2.pdf. Acesso em 25/05/2019.
PORLÁN, R.; RIVERO, A. El conocimento de los profesores. Servilha: Díada, 1998.213p.

PREAL - Programa de Promoção da Reforma Educativa na América Latina e Caribe. Ficando para trás. Boletim da Educação na América Latina, 2002. Disponível em <http://www.preal.org>. Acesso em: 14 dez. 2014.

SANTOS JUNIOR, J. B. (2009) Colaboração Mediada como Ferramenta na Reestruturação do Sistema de Crenças Pedagógicas sobre Ensino e Aprendizagem do Professor de Química. Dissertação de Mestrado, Universidade de São Paulo, São Paulo. Biblioteca Digital da USP, http://www.teses.usp.br/teses/ disponiveis/81/81132/tde-14012010161926/pt-br.php. Acesso em 05/06/2019

SEDU-ES. Secretária de Estado da Educação. Disponível em https://sedu.es.gov.br/Media/sedu/pdf\%20e \%20Arquivos/Curriculo_ES_Ciencias_Natu reza.pdf. Acesso em 08/06/2019. 


\section{Apêndices}

Anexo1- questionário aplicado aos alunos Nome: Data:

Leciona? ( ) sim ( ) não. Se sim coloque o tempo em anos

Escola em que leciona

Púbica ( ) Particular

Série que leciona

Disciplina que leciona

Caro professor ou futuro professor, por favor atribua um valor de importância para cada um dos itens relacionados na tabela no que diz respeito a suas aulas ou futuras aulas. Assinale a concordância ou discordância com as proposições apresentadas, expressando: 3 (concordância total); 2 (concordância parcial); 1 (discordância parcial); ou 0 (discordância total) para cada proposição.

1) Qual o meu objetivo maior em ensinar química/física aos meus alunos?

\begin{tabular}{|l|l|}
\hline Objetivo maior & Valor \\
\hline Para que meu aluno possa se tomar um & \\
individuo dotado da cultura vigente. & \\
\hline Para que meu aluno tenha uma formaçào & \\
eficiente e modema, ou seja, esteja & \\
inserido no mundo tecnológico no qual & \\
todos nós precisamos conviver. & \\
\hline Para que meu aluno se tome um cidadào & \\
critico, ético e atuante no mundo em que & \\
vive. & \\
\hline Para que meu aluno posas enriquecer & \\
progreasivamente seus conhecimentos e & \\
vá aos poucos conseguindo faser & \\
leituras cada vez mais complexas do & \\
mundo em que vive. & \\
\hline
\end{tabular}

2) Que conteúdo de química/física devo ensinar aos meus alunos?

\begin{tabular}{|c|c|}
\hline Conteudo & Valor \\
\hline $\begin{array}{l}\text { Uma síntese dos conceitos químicos mais } \\
\text { importantes. }\end{array}$ & \\
\hline $\begin{array}{l}\text { Uma sintese dos conceitos químicos mais } \\
\text { importantes, combinados com splicaçóes } \\
\text { tecnológicas desses conceitos. }\end{array}$ & \\
\hline $\begin{array}{l}\text { Conceitos químicos presentes nos } \\
\text { fenómenos que se spresentam no cotidiano } \\
\text { do aluno. }\end{array}$ & \\
\hline $\begin{array}{l}\text { Conhecimentos que permitam a integraçá } \\
\text { nos niveis cientifico, social, histórico e } \\
\text { ambiental. }\end{array}$ & \\
\hline
\end{tabular}

4) Como devo ensinar química/física aos meus alunos?

5) Como deve ser a minha forma de avaliar os meus alunos?

\begin{tabular}{|c|c|}
\hline Avaliaçâo & Valor \\
\hline $\begin{array}{l}\text { A minha avaliaçăo deve cobrir o } \\
\text { conté́do trabalhado e com } \\
\text { instrumentos individusis do tipo } \\
\text { provas e listas de exercícios } \\
\text { preferencialmente, } \\
\text { identificar o conhecimento adquirido } \\
\text { pelo aluno durante o periodo. }\end{array}$ & \\
\hline $\begin{array}{l}\text { A minha avaliaçåo deve cobrir o } \\
\text { conté́do trabalhado, os } \\
\text { instrumentos näo precisam ser } \\
\text { especificadamente individualizados, } \\
\text { mas precisam me dar dados } \\
\text { confiaveis para medir a } \\
\text { aprendizagem e analisar o processo } \\
\text { de ensino-aprendizagem. }\end{array}$ & \\
\hline $\begin{array}{l}\text { A minha avaliaçáo deve privilegiar a } \\
\text { mudança atitudinal do meu aluno, as } \\
\text { habilidades e competências } \\
\text { construidas no processo de ensino- } \\
\text { aprendizagem, por isso a minha } \\
\text { observaçâo é um tator } \\
\text { importantissimo. }\end{array}$ & \\
\hline $\begin{array}{l}\text { A minha avaliaçăo deve privilegiar a } \\
\text { evoluçâo dos conhecimentos do meu } \\
\text { aluno no processo de ensino- } \\
\text { sprendizagem; posso utilizar } \\
\text { instrumentos individualizados ou } \\
\text { coletivos, a minha observaçäo. Esas } \\
\text { avaliaçâo também me orienta a faser } \\
\text { as modificaçóes necessárias no } \\
\text { processo, visando urm melhor } \\
\text { rendimento dos meus alunos. }\end{array}$ & \\
\hline
\end{tabular}


Anexo 2- sequência didática: física quântica

Atividade 1 (individual)

- Pesquise sobre o início da física quântica $( \pm 20$ minutos): Tente responder em uma folha separada as seguintes perguntas:

a) Quem era Max Planck?

b) Qual foi o importante trabalho realizado por Planck que marcou o início da Física Quântica?

c) O que é um corpo negro?

d) O que é fóton?

e) Como Planck justificou sua solução para o problema da radiação emitida por um corpo negro?

Atividade 1.1 (em grupo) - Discuta suas respostas com o colega do lado e se necessário, em uma folha separada, coloque suas respostas revisadas. ( \pm 10 minutos)

Atividade 1.2 - Ponderação do Professor: \pm 20 minutos - Após a explicação do professor, anote se necessário, em uma folha separada, suas respostas revisadas.

\section{Atividade 2 - Exercícios de Fixação}

1 (individual) ( \pm 10 minutos). $\mathrm{Na}$ entrega do prêmio Nobel, é tradição que o laureado realize uma conferência apresentando as ideias principais relacionadas ao trabalho pelo qual foi premiado. Em 2 de junho de 1920 (dois anos após receber o prêmio Nobel de Física), Planck realizou sua conferência, relatando sua insatisfação com o próprio procedimento: "No entanto, ainda que a fórmula da radiação se mostrasse absolutamente correta, teria sido, afinal de contas, apenas uma expressão de interpolação descoberta por um feliz acaso de raciocínio, de validade rigorosamente limitada. Por essa razão, eu me ocupei [...], desde o dia de sua formulação, em descobrir o verdadeiro significado físico dessa fórmula [...]; até que, depois de algumas semanas do mais intenso trabalho da minha vida, uma luz surgiu na escuridão e uma nova $e$ inimaginável perspectiva abriu-se à minha frente". (Traduzido da conferência proferida por Planck por ocasião do recebimento do prêmio Nobel de Física de 1918. Disponível em: <www.nobelprize.org/ nobel_prizes/physics/laureates/1918/planc k-lecture. html>. Acesso em: 12 jan. 2013.) Sobre o texto acima responda: O texto refere-se a que aspecto da teoria formulada por Planck?

1.1 (em grupo) ( \pm 5 minutos) Discuta sua resposta com o colega do lado e se necessário, em uma folha separada, coloque sua resposta revisada.

1.2 Ponderação do Professor: \pm 5 minutos - Após a explicação do professor, anote se necessário, em uma folha separada, suas respostas revisadas.

2 (individual) ( \pm 5 minutos) Determine a faixa de energias dos fótons para radiações na região visível do espectro eletromagnético, isto é entre $400 \mathrm{~nm}$ e 700 nm.

2.1 (em grupo) ( \pm 5 minutos). Discuta sua resposta com o colega do lado e se necessário, em uma folha separada, coloque sua resposta revisada.

2.2 Ponderação do Professor: ( \pm 5 minutos) - Após a explicação do professor, anote se necessário, em uma folha separada, suas respostas revisadas. 